\title{
The Final Year Project (FYP) in social sciences: establishment of its associated competences and evaluation standards
}

\author{
Postprint version of Joan Mateo, Anna Escofet, Francesc Martínez, Javier Ventura, \\ Dimitrios Vlachopoulos
}

The Final Year Project (FYP) in social sciences: Establishment of its associated competences and evaluation standards.

Studies in Educational Evaluation, Volume 38, Issue 1, March 2012, Pages 28-34

http://dx.doi.org/10.1016/j.stueduc.2011.12.002

\begin{abstract}
This paper presents the fundamental characteristics of the Final Year Project (FYP), its associated competences and some evaluation standards that derived from a research conducted by the regional government of Catalonia and the Catalan University Quality Assurance Agency. More analytically, the paper begins with the definition of the Final Year Project in social sciences, continues with the identification and analysis of its associated competences and the basic phases for its realization and finishes with the presentation of some fundamental evaluation standards. Our final proposal is considered as objective and effective not only for the realization of the FYP by the students, but also for its evaluation by the instructors, since it can easily be customized for different social sciences curricula.
\end{abstract}

Key words: Final Year Project, assessment, evaluation, competences, higher education, European Higher Education Area

\section{Introduction: definition of the Final Year Project in social sciences}

The guidelines of the European Higher Education Area (EHEA) imply the rethinking of many of the current evaluation systems, since the new pedagogical models are now focused on the learning acquired through the students' personal work and on the establishment of the ideal conditions for them to achieve the learning outcomes of the 
proposed educational objectives. The rapidly expanding knowledge base and the changing demands of work and employment mean that it is desirable (even essential) that these abilities are then generalized beyond the educational context (Cuthbert, 1995). The new era of Higher Education requires the establishment of a comprehensive quality assurance system at every European educational institution. As part of this new system, universities and programs must demonstrate that their graduates have achieved a set of learning outcomes established in each discipline area.

In this context, it has been a standard practice during the last years for social sciences programs to incorporate at least one major assessment exercise in the final (fourth) year of the studies in the form of a project. This Final Year Project is viewed as the culminating learning experience of the undergraduate program, and the quality of student output is often used as an indicator of the quality of the program as a whole (Jawitz, Moore \& Shay, 2002). It is important to mention that the FYP has been well studied in natural sciences and engineering (Orsmond, Merry and Reiling, 2004), where it has become a major component of the departments' curricula (Vitner and Rozenes, 2009). On the other hand, since we cannot find extensive research on this topic in social sciences we consider necessary to define the FYP according to the guidelines of the European Higher Education Area (EHEA) and to adapt this definition to the Spanish / Catalan reality. By Spanish/ Catalan reality we mean that our reference model is the Spanish Higher Education Area which is structured in a 4 year undergraduate level (and not in 3 year as in most of the other systems following the Bologna process).

According to the EHEA, the FYP has to be a research project oriented to the development of a research, an intervention or an innovation in the professional field. Of course innovation in a professional field such as psychology or sociology is almost an impossible task for undergraduate students, since it requires expanding scientific knowledge. By innovation in this level we mean the participation and personal contribution in projects /initiatives coordinated by experts. At this point, it is important to mention that during the fourth year of the Spanish/ Catalan undergraduate studies there is another subject related to the intervention/ innovation in the professional field, the "Practicum", which consists of a combination of some classroom sessions about professional skills and their application in the everyday professional activity and of a 
four month (in most cases) placement for practice and professional training in enterprises, organizations and institutions related to each program). So, the existence of the "Practicum" changes -substantially- the orientation of the FYP, having as main objective to develop students' abilities as scientific researchers. By definition, project work introduces a new problem-solving situation in undergraduate programs, and students have to use their initiative to identify the research problems, decide on the information they need and how to obtain it, use the collected information to solve the research problems and present the results in an adequate way (Kuisma, 2007). The complexity of the Final Year project requires a well defined process that facilitates the students in their completion of the tasks.

In addition, through the FYP, the students have to integrate and apply-with professional, creative and innovative criteria - the competences acquired during these four years of university studies; they have to incorporate new ones, which are related to the two most important subjects of the fourth year of the studies, the FYP and the "Practicum", such as autonomy, initiative, knowledge development, abilities and strategies; and to give solutions to the research problems that derive from the project.

Finally, it is obvious that the concrete characteristics of the Final Year Project will be different among the various undergraduate programs, according to their academic priorities and the professional profile that they would like to give to their students. While these projects may vary greatly in scope and nature (e.g., requiring a large-scale written assignment such as a dissertation or extended essay or the design and production of some type of artifact), it is obvious that the mission of the FYP can vary as well as the ways of preparing it, but we consider that a number of key characteristics must be shared (Todd, Bannister and Clegg, 2004).

\section{Identification of the associated competences of the FYP}

The identification of the competences associated with the FYP was made through the descriptors of Dublin (Joint Quality Initiative, 2004), which helped us obtain a list of 17 competences:

- Identify a topic.

- Conduct a literature review on a specific topic. 
- Establish questions or objectives that can orient the project.

- Identify and organize the fundamental elements of the FYP.

- Distinguish the different phases of the FYP.

- Present and defend in public the progress report to an evaluation committee and/or a group of students.

- Select the fundamental sources for the construction of the bibliography of the project.

- Integrate the necessary knowledge to create the theoretical framework of the project.

- Collect, analyze and interpret the obtained data.

- Demonstrate control over the technical language of the field.

- Demonstrate ability to communicate - in both oral and written form - in at least two languages (mother language and English).

- Develop a correct and adequate report to be orally communicated.

- Get in touch with expert audiences.

- Identify the most important aspect of the project.

- Interpret rigorously the information obtained.

- Respond to the demands of the expert audiences.

- Be aware of the process of the FYP realization by generating new knowledge.

For our research group "a student has acquired a competence when she/he can demonstrate sufficient evidence of learning results related to this competence". We are aware that three basic hazards lurk from the above thesis:

a) Error in representation: the chosen results are not representative of the competence. 
b) Insufficient representativeness: the results are representative, but some important ones are missing.

c) Lack of intensity in the results' achievement: all the important learning results are present but they haven't been achieved with the necessary depth in order to confirm the achievement of the competence.

Due to this last hazard, we consider it very important to raise the issue of "evaluation standards". The determination of an evaluation standard consists of the establishment of the level that has to be achieved, a group of learning results, in order to confirm that the competence associated with them has been acquired. The determination of these standards can be explicit, by trying to describe-in an exhaustive way-the level of achievement that we consider sufficient in order to confirm if the presented evidence corresponds or not to these established requirements. It can also be implicit, by associating an evaluation scale to every learning result and letting the evaluation experts decide the required level of intensity that is needed to achieve this result in order to confirm the acquisition of the associated competence. At this point we consider it necessary to identify the significance of each category of this evaluation scale and to establish the minimum level of achievement for the competences.

\section{Identification of the basic phases of the FYP}

In order to identify the basic phases of the Final Year Project, we made a comparative analysis of relevant documents produced by different European universities, including the Magdeburg-Stendal University (Baumgarten and Hartmann, 2008), the Technische University of Dresden (2007), the Reinisch-Westfalische Hochschule Aachen University (Biegi, 2008), the Freie University of Berlin (2008), the University of Limerick (2003), the Kirchiliche Padagogische Hochschule of Wien (2007), the University of Bath (Harris and Smith, 1983), the Oxford Brookes University (Webster, Pepper and Jenkins, 2000) and the School of Engineering of the United Kingdom (2002). 
After realizing a comparative analysis of the above documents, we created our guide for the design and preparation of the FYP, which concretizes the fundamental activities we consider necessary to be done during each phase. Our guide can be summarized as follows:

a) Phase 1: Topic selection

During this phase, the students have to choose the research topic they want to develop. The topic selection will also determine the tutor who will supervise the FYP, since he/she has to be an expert in the research field of the project. In addition, the student has to prepare a report justifying the selected topic. This report should include the following elements:

- His/her motivation to develop this research topic.

- The scientific relevance of the topic.

- The guarantees for its preparation and the context opportunities.

- The relation between the selected topic and the courses of the undergraduates program.

- The presentation of a basic literature review about the topic.

- The clarification of a first research question and the establishment of the research objectives.

Finally, the student has to present this report to his/her tutor for approval and be able to continue with the development of the project.

b) Phase 2: Planning

During this second phase, the student has to create a work plan that includes:

- The title of the FYP.

- The research context.

- The research objectives (general and specific).

- The methodology and the sources that will be used for the data collection.

- The resources that will be used for the research.

- A more complete literature review about the topic.

- A first version of the table of contents of the Final Year Project. 
Finally during the planning phase, the students have to prepare an activity calendar that should include a chronology with the delivery deadlines for each section of the FYP's index.

c) Phase 3: Development

During this phase, the students have to study in depth the topic's literature and build the theoretical framework of the project by taking into consideration the literature review and the most discussed references during the four years of the undergraduate program. In addition, they have to carry out the field research, by analyzing the results obtained through the data collection instruments, extracting conclusions and determining future prospective for the project. All the mentioned activities have to be included in the first draft of the FYP, which should be accompanied by a progress report concerning the development phase. Finally this first draft should be delivered to the tutor and it should be revised and corrected according to his/her guidelines.

d) Phase 4: Final delivery and presentation

During this fourth phase, the students have to deliver the final and corrected version of the Final Year Project and prepare its public presentation and defense in front of the evaluation committee. The defense is chaired by the FYP Committee Chair who, acting as moderator, rules on questions of procedure and protocol that may arise during the defense. The overall goal is the public presentation and defense of the study. During the defense, the committee explores, with the candidate, the research methods employed in conducting the study, the findings and conclusions of the study, and the contributions the study is expected to offer in the decision making processes. In this way, the candidate and examiners reach a more extensive insight into the candidate's research area.

e) Phase 5: Evaluation, recommendations and orientations 
After the presentation and public defense of the FYP, the students are required to create a portfolio of the learning acquired during the whole process, taking into consideration the orientations and recommendations of the FYP evaluation committee.

\section{Presentation of the first evaluation standards for each competence and phase}

Once the phases of the Final Year Project were defined and concretized, we established some evaluation standards for each one of the associated competences of each phase. These standards can be seen in the table below:

Table 1. The initial evaluation standards for the Final Year Project.

\section{Verification of the FYP phases and their associated competences}

After preparing the first version of the assessment guide of the competences of the Final Year Project, we considered it necessary to verify its fundamental elements with online questionnaires and semi-structured interviews to recognized experts in the field of social sciences. By "experts" we mean people who are known to have done research in this field through journal articles, books, government reports, theses and dissertations. In order to cover more of this population, we chose all the directors of studies of the social sciences departments in the Catalan universities, a total of 71 people.

\section{Method}

As mentioned above, on the one hand we used the Google Docs application to send an ad hoc survey to our target group (the 71 experts). The survey was sent by email together with a presentation letter, in which we explained to them the context and the objectives of our research and a document with instructions about how to answer the survey. This document basically contained the description and justification of the first version of our assessment guide for the evaluation of competences of the FYP in social sciences. 
The survey was divided in two parts. The first part contained six closed questions about the phases of the FYP and the participants in the first five questions had to evaluate (using a Likert scale from 1 to 4 ) the relevance of each phase (topic selection, planning, development, delivery \& presentation, evaluation- recommendations \& orientation). The last question of the first part was an open question that was asking the experts whether they considered adequate this division of the FYP into five phases and if they would add or take out any of them. In the second part, the experts had to evaluate, through 17 closed questions (also by using a Likert scale from 1 to 4), each one of the 17 associated competences we identified in the first version of our assessment guide. Finally, the survey contained an open question asking the experts whether they found correct the identification of the 17 competences during the five phase of the FYP and if they would add or take out any of them.

It is important to mention that, from the 71 selected experts, we received 25 answered surveys (35\%), a number that is considered satisfactory if we take into consideration that it is was a study realized through the Internet. Nevertheless, the reduced number of the participants obliges us to present results globally and not to divide them into segments. The quantitative data of the survey (closed questions) were analyzed with the program OpenOffice-Calc, while the qualitative data (open questions) were analyzed with the program Weft-qda.

In order to ensure sufficient information and comments about our assessment guide, we decided to realize three semi-structured interviews with experts of different social science studies. The interviews were divided into four general parts. The first part was dedicated to the phases of the FYP and the experts were asked whether they believe that we should add another phase (a phase 0 for example as the starting point for the topic selection or a phase 6 comparing the final results of the FYP with the phase 0 , etc.) or combine two phases into one or even take out one phase.

The second part of the interviews was dedicated to the associated competences for each phase of the Final Year Project and we were asking the experts whether we had omitted any important ones, especially as far as the phase two (planning) and the phase three (development) were concerned. In the third part of the interviews we asked the experts 
to evaluate the learning results for each associated competence and to consider if any important results were missing from our guide. Finally, in the fourth part of the semistructured interviews we wanted to know the experts' opinion about whether all these phases and competences were valid for the FYP of all undergraduate programs in social sciences.

\section{Summary of the obtained data}

As far as the survey is concerned, we can say that although we used an ordinal Likert scale from 1 to 4 (1=not relevant, $4=$ very relevant), we believe it is better to present the mean -instead of the median- as the average score of the answers of every question.

In general, all five phases we proposed to the experts were considered very relevant for the preparation and presentation of the Final Year Project (3.42/4). Despite this general acceptance, we observed that phases one and two were considered less relevant than the other three. More analytically, both first (topic selection) and second phase (planning) got an average score of 3.1/4. The third phase (development) had the highest average score (3.75/4), while the fourth (delivery and presentation) and the fifth phase (evaluation, recommendations and orientation) were also considered very relevant by the experts (3.56/4 and 3.60/4 respectively). Finally, the proposals/comments of the experts about the open question of the first part of the survey (about our division of the FYP in five phases and the possibility to add or to take out a phase), can be summarized by the following statements:

- Add also the methodological competences.

- Add a phase 0, as the starting point for the topic selection.

- Add a phase 6, for the self-evaluation of the students.

- Add a competence about the information selection in phase 3.

- Explain better the role of the tutor during the whole process.

As far as the second part of the survey is concerned (about the evaluation of the 17 associated competences to each one of the five FYP phases), we also noticed a high level of acceptance by the participating experts. More analytically, the three 
competences associated with the first phase (topic selection) were considered very relevant (3.40/4), even though one of them received a lower average score:

Table 2. The survey results concerning the competences associated with phase 1 of the FYP.

The three competences associated with phase 2 (planning) received the lowest evaluation (2.9/4), since only one was considered very relevant by the participating experts:

Table 3. The survey results concerning the competences associated with phase 2 of the FYP.

On the other hand, the competences associated with the third phase (development) were highly evaluated, since four out of the five were considered very relevant and one was considered relevant:

Table 4. The survey results concerning the competences associated with phase 3 of the FYP.

Moreover, all the associated competences of phases 4 and 5 were considered as very relevant by the participating experts

Table 5. The survey results concerning the competences associated with phases $4 \& 5$ of the FYP.

Finally, the proposals/comments of the experts about the open question of the second part of the survey (about whether the experts would add or take out a competence from the five phases) can be summarized by the following statements:

- Add a competence related to the methodology of the FYP.

- Add a competence about how the students take advantage the recommendations/orientations of the tutors.

- Give a "lighter" character to the competences of phase 4, since they look similar with the cases of a master's degree thesis.

- It is difficult to think of an evaluation process for the competence of phase 5.

- The Final Year Project is not always a research project, so many of these competences are not needed when it's not.

- For the moment, we do not examine the communication ability in a foreign language.

- Some competences are very broad and they need more delimitation. 
- Add a competence about the personal improvement of the students during the FYP process.

- Depending on the undergraduate program, these competences may be different or their importance may vary.

After the qualitative analysis of the answers given during the semi-structured interviews, we were able to extract the following comments/statements related to each one of the FYP phases:

As far as the first phase is concerned (topic selection), the experts commented that the selection of the topic could be made from a list or topics even though this is not obligatory. Moreover, they proposed to add a "negotiation competence" in this phase, which implies a capacity for reflection about the program of studies and it is related to the itinerary followed by the student during the four years of studies. The students should choose their FYP topic according to the subjects they have coursed, the practices they made and their commitment to this thematic area.

As far as the second phase is concerned (planning), the experts argued that the level of interaction and collaboration between the tutor and the student should be very explicit in the FYP guide. Finally, they found the competence "Identify and organize the fundamental elements of the FYP” very generic.

Moreover, the experts proposed to add a "communication competence" in the third phase of the FYP (development), since the students - in collaboration with their tutorhave to demonstrate their abilities to explain what they are doing and to deal with the tasks proposed by the tutor. Also, the experts proposed to add another competence in this phase related to the personal improvement of the students.

As far as the fourth phase is concerned (delivery and presentation), the experts proposed a more concrete definition of the competence related to the oral expression by indicating also the means and adequate resources used during the oral presentation, depending on the topic's characteristics. 
Furthermore, as far as the fifth phase is concerned, the experts commented that it needs more development by adding a self-evaluation phase and by explaining in a more detailed way the associated competence to "Be aware of the process of the FYP realization by generating new knowledge".

Finally, the experts made some general comments about the guide for the realization of the FYP, which can be summarized by the following statements.

- Thee guide is very well structured and can be used, with small changes, by all social sciences undergraduate programs.

- The guide should change according to the number of credits of the FYP and according to each orientation (research of professional).

- The phases, the associated competences and the learning results have to be presented by a unified syntax.

Final version of the guide of the evaluation standards for each competence and phase

After analyzing the experts' comments from the questionnaires and the interviews, we made some changes to the first version of our guide for the evaluation standards and the associated competences of the Final Year Project. This last version can be seen below:

Table 6. Final version of the evaluation standards for the Final Year Project.

\section{Conclusions}

The learning processes in the undergraduate curricula involve both the acquisition of discipline-specific knowledge and the development and reinforcement of professional skills. According to the new era of Spanish/ Catalan Higher Education, which requires the establishment of comprehensive quality assurance systems at every European educational institution, the fourth year of the undergraduate studies is a fundamental year for the students' academic and personal improvement and their integration into the 
labor market. In order to achieve this objective, two specific subjects are organized, the Final Year Project, basically for the acquisition of the research skills, and the "Practicum" for the acquisition of the professional abilities. Our objective is to offer to the students and academics a methodological framework, where learning and evaluation form part of the same reality. Of course, it is not possible to create an instrument for all the possibilities of the FYP and this is why we focused on its main part, the development of a research.

The Final Year Project constitutes one of the main means for the development of the cognitive and instrumental competences of the undergraduate students, helping the students to learn to carry out the design and development of an empirical work, and to consolidate their acquired knowledge, abilities and attitudes. More concretely, our experience and the contributions of the experts participating in our research made us understand that in the FYP in social sciences the emphasis is given mostly on one way of doing research and one type of research, the deductive field research. Since the FYP presents some peculiar and unknown characteristics for the students, it is important to concretize its definition and evaluation standards in order to help the students to face with success this new challenge at the end of their undergraduate studies.

The preparation of this guide for definition and establishment of the associated competences and evaluation standards of the Final Year Project in social sciences has been a big challenge for our research team, since we had to proceed independently to risk drawing conclusions due to the limited amount of previous research in this field. In this context, we have presented an approach to the definition of the Final Year Project by analysing all its important aspects within the European Higher Education Area and by explaining its specific characteristics and phases in order to help students and tutors understand its role and basic functions within the undergraduates programs of social sciences, in spite of being aware of the fact that the FYP can have different mission in each program and different ways of preparation and assessment.

Moreover, we have identified all the competences associated with the FYP in order to prove that they can play the role of a culminating learning experience in an undergraduate program in social sciences, since these competences are often used as indicators for the quality of the students' learning and the quality of the academic 
programs as a whole. Since in the Spanish/ Catalan Higher Education Area the FYP's main objective is the development of the students' abilities as scientific researchers, we focused mainly on these competences and on one specific way of doing research, the deductive research.

In addition, we consider that our proposals can be easily adapted to any social sciences curriculum and that they include all the necessary elements of the FYP for its final assessment.

Finally we believe that this paper opens a window for further debate in this field, which can help us improve and complete our guidelines for the evaluation of competences of the Final Year Project through the exchange of similar research experiences and practices.

\section{References}

Baumgarten, K. \& Hartmann, T. (2008) Leitfaden zur Planung un Erstellung der Bachelorarbeit. Available online at: www.hs-magdeburg.de/fachbereiche/fsgw/studium/Gesundfm/Fragen/LEITFADEN_BACHELORARBEIT_03 2008.pdf (accessed 15 August 2010].

Biegi, M. (2008) Leitfaden Bachelorarbeit fur Studierende. Available online at: www.ipw.rwth-aachen.de/ba/ba leit arbeit tx.pdf (accessed 14 August 2010).

Cuthbert, K. (1995) Project planning and the promotion of self-regulated learning: From theory to practise. Studies in Higher Education, 20(3), 267-277.

Freie Universitat Berlin (2008) Leitfaden fur Bachelorarbeit und Prufungen an der Arbeitsstelle Kommunikationspolitik/ Medienokonomie. Available online at: www. Polsoz.fuberlin.de/kommwiss_institut/kommunikationspolitik/lehrmaterialien/allgemein es/Leitfaden_Bachelorpr_fung_2008.pdf (accessed 15 August 2010).

Harris, D. \& Smith, B. (1983) Undergraduate Project Work. Assessment and Evaluation in Higher Education, 8(3), 246-261. 
Jawitz, J., Moore, R. \& Shay, S. (2002) Management and assessment of final year projects in engineering. The International Journal of Engineering Education, 18(4), $472-478$.

Joint Quality Initiative (2004) Shared Dublin descriptors for the Bachelor's, Master's and Doctoral awards. Available online at: http://www.jointquality.nl/ (accessed 12 August 2010).

Kirchliche Padagogische Hochschule (2007) Leitfaden Bachelorarbeit. Fahrplan zur Bachelorarbeit. Available online at: www.erpa.at/files/File/Leitfaden\%20 Bachelorarbeit.doc (accessed 14 August 2010).

Kuisma, R. (2007) Portfolio assessment of an undergraduate group project. Assessment and Evaluation in Higher Education, 32 (5), 557-569.

Orsmond, P., Merry, S. \& Reiling, K. (2004) Undergraduate project work: can directed tutor support enhance skills development? Assessment and Evaluation in Higher Education, 29 (5), 625-643.

School of Engineering (2002) Project Handbook. Available online at: www.projectsquared.lboro.ac.uk/resources/project_handbook.doc (accessed 15 August 2010).

Technische Universitat Dresden (2007) Leitfaden fur das Exposé zur Bechelorarbeit. Available online at: www.tudresden.de/die tu dresden/fakultaeten/ philosophische fakultaet/ikw/stu/semap/ss07/reflexion/Exposee anleitung.pdf (accessed 12 August 2010).

Todd, M., Bannister, P. \& Clegg, S. (2004). Independent inquiry and the undergraduate dissertation: perceptions and experiences of final-year social sciences students. Assessment and Evaluation in Higher Education, 29(5), 335-355.

University of Limerick (2003) Final Year Project Handbook. Available online at: www.mic.ul.ie/foi/FYP\%20Revised\%20Handbook\%20V.5\%2013.02.03.htm (accessed 10 August 2010). 
Vitner, G., Rozenes, S. (2009) Final-year projects as a major element in the IE curriculum. European Journal of Engineering Education, 34(6), 587-592.

Webster, F., Pepper, D., and Jenkins, A. (2000) Assessing the Undergraduate Dissertation. Assessment \& Evaluation in Higher Education, 25 (1), 71-80. 